\title{
Customer Expectations: Concepts and Reality for Academic Library Services
}

\section{Christopher Millson-Martula and Vanaja Menon}

\begin{abstract}
As academic libraries continue to evolve as service organizations, they should focus on their users as customers and develop programs of service that meet or exceed user expectations. The overriding goal will become customer satisfaction. This article deals with the elements that determine expectations as well as the existing gaps that relate to customer expectations and service performance. Possible strategies for narrowing these gaps include enhanced communication between the library and its customers and improved management.
\end{abstract}

ver the past two decades technological innovations have provided libraries with the means to not only meet but also surpass customer needs and expectations. Initially, technology involved the automation of library staff functions, and customers experienced few benefits directly. With the development of the online catalog, customers experienced a faster, easier, and more efficient method of searching. As online systems became commonplace, librarians began to realize the new and exciting possibilities to which increased automation can lead. The flexibility of electronic data led to shared catalogs, dial access, and remote charging, thereby allowing customers to search multiple catalogs remotely, even from the comfort of their own homes or offices. In addition, the use of telefax machines has dramatically reduced the turnaround time for the remote processing of photocopy requests. Innovations such as full-text databases and document delivery systems are increasing.
Consequently, students and faculty have experienced directly the benefits of technology through enhanced student performance and increased faculty productivity.

However, while these and other advances successfully have increased customer satisfaction, they have likewise raised customer expectations. As a result, academic libraries should be searching constantly for new ways to keep up with those expectations. Multimedia products and an explosion of networked information add a whole new level of complexity for information seekers and providers alike. Unfortunately, this complexity, coupled with today's financial constraints, often makes it difficult to decide which products and services are best for the library. Blindly embracing sophisticated technology does not necessarily translate into optimal or even enhanced service. Rather, academic librarians should implement technology within the context of a grand service vision that library staff and customers

Christopher Millson-Martula is Associate Librarian at the Fletcher Library, Arizona State University West, Phoenix, Arizona 85069-7100. Vanaja Menon is Associate Librarian at the Donnelley Library, Lake Forest College, Lake Forest, Illinois 60045. 
have jointly established on the basis of customer input and feedback. It is crucial for academic librarians not to forget the customers for whom these services exist.

\section{CUSTOMERS AND LIBRARY SERVICES}

Charles Osburn describes the situation quite succinctly when he says that library researchers (and libraries) have "not focused so much on the consumer's goals, methods, habits, and motivations as we have on the efficiency of techniques to control and retrieve to our own professional satisfaction." ${ }^{11}$ Likewise, Douglas Zweizig states explicitly that the majority of library research essentially has ignored the user. ${ }^{2}$ This article will attempt to assist library staff as they transform libraries into service organizations. To do this successfully, it is necessary to not only focus on library users as mere customers but also to provide a program of services that will either meet or exceed user expectations.

In almost all instances, libraries have possessed a long and commendable record as service organizations. Libraries continuously implement new programs and services with the hope that these may succeed in satisfying expressed or unexpressed needs of some group or groups of users. Many libraries, particularly academic libraries, have established liaison outreach programs in an attempt to get to know users better while also providing them with a greater amount of information about library programs and services on a more consistent basis. In all of these cases, the goal has been to provide relevant and high-quality services to library users. However, an element of quality service is still absent. That element is the incorporation of users' personal needs and expectations into the development of the service. This requires librarians to establish an ongoing relationship with their customers in order to learn what their needs and expectations are. Staff become active listeners who then are able to process customer input on a continuous basis.

\section{CUSTOMER NEEDS AND BEHAVIORS}

Over the years, library staffs have identified user needs and their corresponding information-seeking behavior. Public librarians and information scientists or librarians working with scientists or other scholars, especially those librarians in the United Kingdom in the 1960 s and 1970s, have played a leading role in this area. In addition, the Association of Research Libraries' Office of Management Studies has fostered an interest in this area by exhorting academic librarians to make use of surveys and other methods that effectively can gauge user needs. While one goal of a user study is to identify user needs, an equally significant one is to eliminate or, at the very least, lessen any obstacles that may hinder users from satisfying their information needs. Russell Shank has advocated using scholars' information needs and informationgathering behavior as the principal guide for determining the needs of the general populace of academic library users. ${ }^{3}$ However, since an academic library's various constituencies possess differing needs and expectations, this could be quite inappropriate for graduate students in a research university or for undergraduates in a four-year or community college.

The continued success of a service organization such as an academic library depends upon the organization's ability to adjust its products and services to correspond to user needs. Academic librarians need to realize that student and faculty needs do change. The change may not be radical or monumental. However, even in the case of subtle or evolutionary change, it remains incumbent for librarians to: (1) be aware that needs are changing; (2) understand the nature of the changes; and (3) realign or reconfigure services to ensure that they remain relevant to the recently developed needs. One such change in needs has involved a shift in user orientation from physical formats containing information to the information itself combined with access to it. Academic 
libraries have responded favorably to this change by creating the collection development continuum of just in time and just in case as well as the broader concept of the virtual library in which users obtain information via electronic access and retrieval with little regard for the concept of ownership.

Let the authors now examine the concept of needs. Andrew Green, who provides an overview of user needs, maintains that a needs assessment should produce a less partial account of what a situation requires. ${ }^{4}$ This is so because needs generally should be more objective than wants or demands. Needs are elements that are instrumental. If their needs are not met, people may fail to attain a goal or an end state. Needs are likely to be at least partially based on reason or logic. Consequently, needs are usually contestable and can be debated or disputed. Lastly, needs are not always expressed because a person can legitimately need something without being aware of the need or desiring the needed item. When allocating library resources, Green thinks that the determining factor should be needs rather than wants or demands, if they can be ascertained.

In contrast, wants tend more to be superficial and instinctive. Accordingly, they cannot be disputed; only the individual in question can state what she or he wants. Likewise, a want can exist in an individual's mind without being translated into a demand for a particular library service.

In conclusion, both Green and others such as Donald King and Vernon Palmour believe that librarians should think less of the need for discrete bits of information and more of informationseeking behavior that is intended to fulfill more fundamental needs. ${ }^{5}$ These needs in turn could be considered as user specifications: needs such as accessibility, turnaround time for information retrieval timeliness, relevance, accuracy, and precision. As Green suggests, another reason why it is prudent for academic libraries to focus on users is that doing so will enable libraries to direct attention to the prior needs that underlie the information needs themselves. ${ }^{6}$

\section{THE CUSTOMER AS AN INDIVIDUAL}

As funding agencies require a greater degree of accountability by academic libraries and as users become more sophisticated and more demanding customers, academic libraries face the need to evaluate services in terms of their effectiveness in supporting the institutional mission. In virtually all cases, this mission cannot be supported without meeting the needs of library customers. Consequently, a direct causal relationship exists between an effective program of services and meeting customers' information and other needs. Green adds that "a correct identification of needs is an essential preliminary to the devising of appropriate means to judge the effectiveness of a library or information service. ${ }^{\prime 7}$ Others have supported this view as well. Philip Rzasa and Norman Baker believe that the primary goals of an academic library are to maximize user need satisfaction while simultaneously minimizing the amount of time and other costs that users must expend to have their needs met. $^{8}$ Likewise, Robert Burns, in advocating library use as a performance measure, believes that while the key to high-quality service is users and their response, the library must view the user as an individual rather than a mere statistic. ${ }^{9}$ Lastly, Jeffrey Disend takes the broader view that evaluation should be linked to customers' expectations in addition to their needs. ${ }^{10}$

Clearly, academic libraries would do well to study in great detail the relationship that they have with their customers. In truly enhancing the efficiency of library services, total quality management takes into consideration customer needs and expectations. Total quality management has advanced many organizations, including libraries, light years forward in terms of enhancing the relationships they have with their customers as well as the services they provide. Academic librarians need to ensure that operations-focused activities do not 
divert the emphasis away from library users as customers or consumers. One unintended effect that sometimes occurs has been to limit efforts to understand user needs and expectations. ${ }^{11}$ Thus, librarians must be careful to view and appreciate total quality management projects in a balanced perspective. The library will realize the full benefits of total quality management only if it employs the concept in concert with ongoing efforts to understand library users.

\section{Total quality management has advanced many organizations, including libraries, light years forward in terms of enhancing the relationships they have with their customers as well as the services they provide.}

Academic libraries, along with other libraries that have a relatively high degree of captive customers (that is, individuals who may possess few options for meeting their information-related needs), should make a special effort to understand their users. Whether using survey instruments, interviews, focus groups, or other assessment methods, academic librarians can gain insight into their customers' needs by understanding: (1) their overall attitudes; (2) the context or environment in which customers use library services; and (3) their perception of how library services are linked to other services. Thus, when a library is willing to learn extensively about its customers' needs and expectations, it can play an active role in shaping user behavior and expectations. As Adamson has pointed out, exceeding customer expectations can have a snowball effect leading to better impressions, higher expectations, and higher perceived value. ${ }^{12}$ This constitutes an especially significant payoff for academic libraries whose budgets have not fared well over the past few years or that have been forced to assess some type of student use fees to maintain a respectable level of services. Highly satisfied stu- dents and faculty may rally to support the library when academic administrators are forced to make significant budget cuts.

\section{CUSTOMER EXPECTATIONS}

To benefit from this payoff, academic libraries must be able to describe their operations with the following equation: service performance > expectations. The key term in this equation is expectations. According to a trio of researchers, Valarie Zeithaml, A. Parasuraman, and Leonard Berry, who are prominent in the field of customer expectations, expectations are the standards against which a firm's performance should be judged. ${ }^{13}$ Is there any reason why the same should not be true for academic libraries as not-forprofit service organizations?

Before embarking on a more extensive discussion of expectations, the authors would like to offer a definition so that there is a common understanding of what is involved. Expectations are assumptions about the likelihood of something occurring; coupled with these assumptions is the acknowledgment that the outcome may not be as expected. More concisely, expectations reflect anticipated performance.

Researchers in the field of customer expectations agree that, in most cases, customers hold expectations that can be considered quite basic. In general, customers expect a basic, solid performance and promises that are kept. Stated differently, customers desire a quality or accurate product or service provided in a friendly and courteous way.

A. Parasuraman et al. place customer service expectations into two categories. ${ }^{14}$ The first deals with service as an end result, outcome, or product. This dimension involves reliability, or the ability to perform a promised service both dependably and accurately. The researchers believe that customer expectations cannot be met if this all-important dimension is lacking. Four other dimensions comprise the second category, that of service process, and these dimensions are important in exceeding customer expectations. First among these is assur- 
ance-the ability of employees to convey a high degree of trust and confidence based on the employees' knowledge and courtesy. Next is responsiveness. Expectations are likely to be exceeded if employees consistently demonstrate a willingness to help customers and provide prompt service. Related to responsiveness is empathy. Employees will exceed their customers' expectations when they demonstrate empathy by providing caring individualized attention to customers. Last is a group of tangibles consisting of elements such as the appearance of physical facilities, the amount of equipment and personnel, and the degree of communication that exists between the organization and its customers.

For each dimension of expectations, a customer is likely to establish two service levels. The first is the desired service level, which is defined as what the customer hopes to receive, a blend of what the customer believes can and should be. The other level is the adequate service level, which consists of the service that a customerwill find acceptable. Acustomer'szone of tolerance falls between these two levels. Quite logically, service expectations are likely to increase with a corresponding increase in a customer's experience. When a customer either lacks many options or does not possess a clear understanding of what options exist, expectations are likely to be appreciably lower.

If academic libraries are to meet and exceed customer expectations more successfully, they need to know what elements determine expectations. Zeithaml et al. offer four key factors: (1) what customers hear from other customers; (2) individual characteristics and circumstances relating to personal needs; (3) experience with using a service; and (4) communications from service providers to customers. ${ }^{15}$ The third factor is multifaceted in that customers will not base their expectations solely on experience with one academic library, but will also consider experiences with other libraries as well as providers of other types of services.

A commonly held belief is that the customer is always right. However, the opposite is more likely the case; custom- ers often hold unrealistic expectations. Cross-service comparison, that is, comparing one service provider with providers of other types of services, can often account for customers' unrealistic expectations. If we apply Kathleen Sanford's concepts to libraries, customers may not always understand the policies and procedures under which a library operates. ${ }^{16}$ Likewise, customers may not realize that such policies and procedures may be essential to the library's survival. Finally, certain policies and procedures may be required for reasons beyond the library's control. In any case, these situations can lead library customers to have unrealistic expectations, which, if not adjusted, will result in customer dissatisfaction. Therefore, it is incumbent upon academic libraries to do all within their power to minimize the occurrence of customer dissatisfaction based on unrealistic expectations.

Clearly, the library environment involves three interrelated elements: customer expectations, library performance, and customer satisfaction. What is central to all three is the customer, whether an individual consumer or a corporate customer. When undertaking research concerning customer expectations or satisfaction, evaluating the quality of services rendered, or implementing actions aimed at enhancing the level of customer satisfaction, academic librarians need to keep in mind that the key is focus. Academic librarians first must identify who their primary customers are. Then they can learn the needs and expectations of their customers as well as evaluate the level of customer satisfaction with library services.

\section{CUSTOMER EXPECTATIONS, LIBRARY PERFORMANCE, AND CUSTOMER SATISFACTION}

Virtually all academic librarians strive to provide their customers with a superior level of service. However, many fail to realize that it is impossible to do so without first comprehending what their customers' expectations truly are. This is because of the interrelatedness of the three elements mentioned above: 
expectations, performance, and satisfaction. Customers' evaluations of library performance and their level of satisfaction with that performance will be based largely on a comparison of expectations with perceptions of the service provided. Many academic libraries have both individual consumers (students, faculty, administrators, and staff) as well as corporate bodies as customers. Research has indicated that minimal differences exist between expectations and perceptions held by individual and corporate customers. Parasuraman et al. conducted sixteen focus group interviews in five cities. ${ }^{17}$ They interviewed both individual and corporate customers of service providers in such diverse areas as insurance, business equipment repair, truck/tractor rental and leasing, auto repairs, and hotels. Their results indicated no significant differences based on the type of customer.

While it is essential for academic libraries to meet customer expectations, this usually involves no more than the mere provision of the right product or service, whether reference and information services, bibliographic instruction, interlibrary loan/document delivery, or a relevant collection of materials. Instead, academic libraries should attempt to exceed the expectations of their customers. This often involves surprising or delighting their customers, doing the unexpected, or providing in a unique way something that their customers consider significant.

Let us now focus on customer satisfaction. Simply put, customer satisfaction represents the difference between what customers expect and what they get. While the level of satisfaction logically should be based on an objective evaluation of the service provided, that is not the case. Rather, satisfaction tends to be based on perceptions, which may not always be logical. It is these perceptions that also define exceptional service, and it should be remembered that the customer, not the library, is the arbiter of exceptional service.

Before examining in detail the gaps associated with customer satisfaction, academic librarians first need to understand the factors or antecedents responsible for customer expectations as manifested in desired and adequate service. Zeithaml et al. identify six antecedents of desired service and five for adequate service. ${ }^{18}$

\section{When a customer either lacks many options or does not possess a clear understanding of what options exist, expectations are likely to be appreciably lower.}

The principal factor responsible for defining desired service is what are known as enduring service intensifiers. Consisting of elements such as a personal service philosophy and service expectations that are either derived from or driven by another party, these intensifiers lead the customer to a heightened sensitivity to service. Their ultimate effect is to elevate the level of desired service. Joining these intensifiers are a customer's personal needs and explicit service promises or service-related statements that the library may have made to its customers. Not to be overlooked are implicit service promises that the library may have made-elements such as service price or tangibles associated with the service. The two remaining antecedents are: (1) word-of-mouth communication, or information about service performance that individuals have personally related to their friends, associates, or acquaintances; and (2) a customer's past experience with library performance.

One of the antecedents of adequate service is predicted service, that is, that level of service which customers believe they are likely to get. Other antecedents of adequate service include transitory service intensifiers, those temporary, short-term factors relating to a customer's situation, needs, or problems that influence a customer's expectations for adequate service. The presence of perceived service alternatives will likewise influence the level of adequate service. When a customer thinks that 
service alternatives to one provider exist, the level of adequate service is likely to be higher than when the range of options is limited. Likewise, situational factors consisting of factors or circumstances beyond the control of the service provider will tend to depress the level of adequate service. The final antecedent involves customers' perception of the degree to which they directly influence the level of service provided. When customers believe that they exert some influence, the level of adequate service should rise.

A customer's degree of satisfaction with a service will evolve as the customer develops a relationship with the service provider. When a customer first establishes such a relationship or is dealing with a new product or service from a provider with whom a relationship already exists, actual performance, rather than expectations, should act as the primary determinant of satisfaction. At this point, the situation is somewhat tenuous because these early expectations are usually not held with a great deal of confidence.

\section{When customers believe that they exert some influence, the level of adequate service should rise.}

As a customer's experience with a service provider continues to grow and results in a substantial accumulation of past performance information, there should be a corresponding increase in both the accuracy and confidence of expectations. ${ }^{19}$ At some point, a rough equilibrium between expectations and performance perception should result as the two become virtually indistinguishable. With a continued increase in service experience and with the ongoing maturation of a service, customer expectations should become even stronger as does their effect on the level of customer satisfaction. Thus, as students and faculty develop greater experience with library services, it is more likely that not only will they become quite satisfied with those services but also that their level of satisfaction will increase progressively.

The relationship between customer expectations and perception of performance or level of satisfaction is multifaceted and complex. When performance falls within an acceptable range of expectation, expectations are likely to dominate the perceptions of satisfaction. ${ }^{20}$ Likewise, when the gap between expectations and performance is relatively small, a customer's perception of performance is likely to migrate toward the customer's expectations. On the other hand, when performance falls outside an acceptable range, a contrast occurs and perceived performance assumes primacy over expectations.

\section{GAPS INVOLVING EXPECTATIONS, PERFORMANCE, AND SATISFACTION}

Academic librarians should study the concept of disconfirmation, which represents the gap between customer expectations and service performance. Researchers have demonstrated that this gap is more responsible for the customer's level of satisfaction than the actual service performance itself. ${ }^{21}$ Thus, while academic librarians should continue to strive to provide the highest quality service possible, they should also be grounded in reality by acknowledging that the perception of the relationship between expectations and performance is most responsible for a customer's assessment of overall service quality.

Zeithaml et al. have conducted extensive research in this area, and they have identified four gaps:

- Between actual customer expectations and management's perception of customer expectations

- Between service quality specifications and management's perception of customer expectations

- Between service delivery and service quality specifications

- Between service delivery and external communications relating to it. ${ }^{22}$

Let us now look at each gap in some detail, giving special attention to the factors responsible for each gap. A later sec- 
tion will present some remedies for closing the gaps.

\section{GAP 1}

The first gap, between customer expectations and management's perception of those expectations, can be considered the most basic. If librarians inaccurately gauge the expectations of students or faculty, it becomes virtually impossible for performance to exceed true customer expectations, and it will be quite likely that the overall customer satisfaction level will be lowered. This gap can be described as stemming from a lack of appropriate interaction between librarians and students and faculty. While librarians generally may believe they know of their customers' expectations and opinions, they often lack specific data to support this belief.

This gap can be attributed to three principal factors: (1) lack of extensive marketing research addressing customer needs and expectations; (2) inadequate (whether lacking in quantity or frequency) upward communication from the front-line service providers at the circulation, information, reference, and other service desks to library administrators; and (3) too many levels of administrators separating the staff providing service from top administrators. For many academic libraries, especially college libraries, the organizational hierarchy is not so extensive as to be unduly weighty. However, there may be widespread reluctance to undertake, with some degree of frequency, major efforts at obtaining input from and information about student and faculty customers. Academic librarians frequently make the argument that customers will simply not tolerate surveys, interviews, focus groups, or other like demands upon their time. They also maintain that they already know what their customers need. Nevertheless, in an imperfect world, other service providers or producers of goods have benefitted considerably from major marketing research efforts, and there is no reason why the same should not be true for academic libraries. Concerning the second factor of upward communication, our experience has been that while service providers are often eager to forward customer input or customer-related information to top management, they too frequently have been given the message that such information is neither valued nor welcome.

\section{GAP 2}

The second gap technically is described as existing between service quality standards and management's perception of customer expectations. In layperson's terms, however, it is simply defined as the gap that results when an organization establishes the wrong service standards, that is, service standards that do not accurately or consistently reflect customer expectations. Zeithaml et al. cite four reasons for the second gap: (1) inadequate commitment to service quality; (2) a lack of perception of feasibility; (3) the infrequent or too limited use of technology to standardize various service tasks so that library staff can guarantee to students and faculty that they will provide consistent quality service; and (4) the absence of goals that are directly related to or based on customer standards and expectations.

Academic librarians have long expressed at least a verbal commitment to service quality. However, each librarian needs to reflect upon the degree to which this verbal commitment is actually translated into actions or behaviors. Likewise, academic libraries, especially research libraries, have played a leadership role in using technology to standardize service tasks. Nevertheless, librarians need to remember the customer and service elements when implementing technology initiatives. Significant service enhancements that result from the total quality management initiatives currently so prevalent among academic libraries definitely should improve this situation. These projects should also improve academic librarians' records of setting goals that are customer-oriented.

\section{GAP 3}

Total quality management also should be beneficial for narrowing the gap be- 
tween actual service delivery and service specifications or standards. This gap relates most directly to library staff as service providers - their training, motivation, abilities, and attitudes. A number of factors could be responsible for this gap. Key among them are: (1) employee role ambiguity which includes uncertainty about what library supervisors or managers expect from staff in direct service positions as well as a lack of information needed to perform the job adequately; (2) a poor employee job fit because of a lack of training or skills needed to perform the job combined with the use of inappropriate tools or technology; (3) a major role conflict for staff who perceive that they are unable to satisfy all of the demands of their internal and external customers; and (4) a supervisory or management system that focuses solely on output, that allows staff few options or too little flexibility in resolving service problems, and that does not convey the sense that management truly cares about staff.

There is generally ample room for academic library management to improve upon situations characterized by views of staff as tools or agents of production who cannot be entrusted with a reasonable degree of decision-making responsibility and authority. Likewise, library managers need to ensure that they provide staff with the full range of resources, including the necessary training, that staff need to carry out their responsibilities and provide the level of service that students and faculty have a right to expect.

\section{GAP 4}

The last gap, officially described as the gap between service delivery and external communications relating to it, can be rephrased as the situation that exists when promises don't match delivery. Factors contributing to this gap include a propensity to overpromise in terms of service delivery and inadequate horizontal communication. A prime example of the former factor involves automated, integrated systems featuring online public access catalogs. Academic librarians quite understandably promote the nu- merous benefits of such systems to students, faculty, and other library customers. Yet, especially when these systems are first brought up, their operational failure because of circumstances generally beyond the control of library staff prevents libraries from delivering what has been promised, whether explicitly or implicitly. Likewise, horizontal communication between library staff and customers can also impede service delivery at a level equal to that which had been promised. This situation is often manifested when staff provide customers with misinformation about the standards relating to the delivery of a particular service. One such instance exists when staff knowingly provide customers with a too idealistic or optimistic estimate of the time required for completion of a document delivery or interlibrary loan transaction. Such information tends to raise expectations on the part of students or faculty, which often are not met when the delay exceeds the time initially projected.

\section{STRATEGIES FOR ENHANCING CUSTOMER SATISFACTION}

Having learned the nature of these four gaps and the principal factors responsible for them, academic library staff can then explore what strategies can be implemented to narrow these gaps. While the idealistic goal would be to eliminate them, a more realistic and feasible one would be to reduce the size of the gaps.

While there are definitely specific actions that academic librarians should take to narrow the gaps between expectations and service quality, it will be necessary to adopt a major ideological or attitudinal change. Academic librarians need not be hesitant to admit that it is essential to implement a proactive stance employing many of the marketing and research techniques of for-profit firms.

Before implementing such techniques, however, academic librarians need to ensure that they have established a vision of service with which all staff can identify and which serves as the driving force 
behind all library programs and services. Employees in the public sector or not-for-profit settings need to believe that what they do and how they perform matter considerably. Instead of merely representing the organization, they are the organization. Not-for-profit employees, such as academic librarians, must believe that they can make a difference. Although students and faculty are not required to pay directly for most of the library services that they use, library staff must realize that staff are responsible for the service quality and response time that the library provides. Thus, the element of accountability is introduced as it relates to the nonmonetary prices that library customers must pay for services.

\section{Although students and faculty are not required to pay directly for most of the library services that they use, library staff must realize that staff are responsible for the service quality and response time that the library provides.}

Over ten years ago Russell Shank advocated that academic librarians adopt a cardinal rule of marketing: don't simply ask customers to identify their needs or wants but also offer a full menu of products and services that provide customers with alternatives from which they can choose..$^{23}$ Put another way, academic librarians may need to tell customers what they ought to expect from the library. This relates to the practice, which is widespread in consumer industries, of actually managing expectations to enhance perceptions of service. Zeithaml et al. state:

A major premise of our research has been that consumers' perceptions of service quality can be influenced either by raising consumers' perceptions or by lowering expectations. Managing customers' expectations, especially those created by the company itself through external communications and price, is an essential part of a strategy to attain perceived quality service. ${ }^{24}$
While the entire issue of meeting customer expectations clearly involves aggressively offering programs and services, there also exists a reactive element of identifying those expectations. To identify expectations successfully, academic librarians must demonstrate the innovation needed to identify or create new products or services that address students' and faculty members' previously unmet or even sometimes unrecognized needs.

This leads us to the two major areas in which academic librarians need to act: customer relations and management. No academic library will enhance its success in meeting student and faculty expectations without first establishing an ongoing and major relationship with those customers.

Joan Uhlenberg states that the only way to advance in either meeting or exceeding customer expectations is to gain an in-depth understanding of customers and their behavioral needs. ${ }^{25}$ Before getting closer to customers, however, librarians first need to identify their customers (which should not be too difficult for most academic librarians) and learn how they use library services. In addition, librarians should encourage students and faculty to define clearly their service requirements. Certainly, the library's overall capabilities together with librarians' commitments to provide new and creative levels of products or services are key elements. Yet a superior understanding of customers is what Uhlenberg considers most critical.

When an academic library has developed a genuine customer relationship with students and faculty, a likely result is a greater level of tolerance on the part of library customers coupled with a narrowing of the gap between customer expectations and the level of library services provided. A requisite for such a relationship is for academic librarians to learn considerably more about the students and faculty who constitute their primary customers. It is not sufficient simply to research what customers need or want or how they behave when seeking information. Rather, academic li- 
brarians also need to understand how to make the best use of research to improve the quality of their service. Thus, academic librarians need to implement a management information initiative consisting of the identification of the data they need to make effective and efficient program/services decisions as well as the methods to be used for gathering and analyzing the relevant data. Following that, they must make a commitment to actually use the data when making a decision rather than simply burying the data in files or reports.

Without effective communications, customers are free to form their own expectations, which may or may not be realistic. Unmet expectations not only cause dissatisfaction but also erode trust. A successful relationship between academic librarians and their customers that is based upon open, regular, twoway communication includes trust as a key element. This enables librarians to effectively address customer expectations, to the mutual benefit of both customers and the library.

A principal approach to both earning trust and dealing with expectations is to manage promises. Librarians consistently must present honest and reliable messages about what they can and cannot do. It is essential that librarians not give students and faculty unrealistic expectations and then fail to meet them. Academic librarians must first determine what is possible in the area of service delivery, communicate that service message to students and faculty, and lastly deliver the service as promised.

It is not sufficient to simply provide information about the library's products and services. Rather, it is necessary to define the library's products and services and to show students and faculty what benefits they get from using the library. Moreover, academic librarians should seriously consider offering a multitiered structure of products and services. At one end would be a quicker, more generic level of service provided at the information desk staffed by generalist librarians and library assistants. The other end of the spectrum would be characterized by highly specialized indepth reference or research support services provided by subject specialists on an appointment basis.

If students and faculty hold unrealistic expectations of librarians and library services, it may be because of a comparison they have made with providers of other types of services. Therefore, a comprehensive information program relating to products and services should alleviate this problem considerably. While such a program should greatly enhance the knowledge base of students and faculty, librarians ought to consider a formal education program in addition to a program of bibliographic instruction. Thus, academic librarians should educate students and faculty about when they are likely to need the library's products and services as well as how they can be used most effectively. Not to be excluded is a description of the service delivery process, providing an appropriate and not overwhelming amount of information that explains the reasons for policies or procedures that could frustrate students and faculty. Along with an explanation of the process, customers likewise need to know what is expected of them in service delivery transactions.

\section{STRATEGIES FOR ENHANCED COMMUNICATION}

Let us now turn to specific ways in which academic librarians can either initially establish or further enhance their communications with students and faculty. Library staff who occupy prime public contact positions are key players in establishing more effective communications between the library and its customers. These staff members can serve as essential conduits of information in either direction, and they would do well to record customer compliments, complaints, concerns, needs, and expectations, at least on a periodic basis. From their vantage point, these staff can act as both extensions of their customers and advocates for customers' needs.

Academic librarians need to engage in a wide range of market research activities that will help identify customer 
needs and expectations. Focus groups have been shown effectively to provide insights and perceptions of service quality. When working with focus groups, academic librarians should attempt to include not only experienced and inexperienced users but also nonusers as well because the latter may have turned to alternate service providers. Other means include one-on-one interviews with customers, questionnaires, and complaints or compliments logs. One area in which most academic librarians could register improvement involves the strategic use of complaints. While it is easy to acknowledge and respond to customer complaints, how often are the situations identified in complaints analyzed with the aim of instituting improvements? Complaints can serve as an inexpensive and continuous source of adjustment to the service delivery process, and they give top managers a chance to hear complaints directly from customers. British Airways not only established customer complaint booths at its Heathrow Airport hub but customers also have the opportunity to record their complaints on video. However, complaints should be placed in the proper perspective. Zeithaml et al. report that less than 5 percent of customers with service delivery problems formally register complaints with the service providers. ${ }^{26}$

Academic librarians have made frequent use of survey instruments to obtain customer input. However, the definition of customer should be expanded to include not only students and faculty but also the library staff, who, as internal customers, also receive service from their colleagues. Surveys obviously should attempt to measure customers' overall satisfaction. Loews Hotels currently uses a customer satisfaction survey that is centered exclusively on customer expectations. More specifically, surveys should focus on staff courtesy and competence. In addition, libraries should give more attention to tracking customer satisfaction with individual service transactions by surveying customers immediately after the completion of the transaction.
Finally, most academic librarians have considerable experience with library committees as conduits of information. To address customer needs, wants, and expectations more adequately, librarians should consider the creation of customer panels representing segments of customers. The key here is to view customers as forming segments based upon their differing needs and situations.

Perhaps most significant is the need not only to establish but also to maintain daily contact with a changing segment of a library's customer population. In smaller academic libraries, most staff are in direct contact with a significant percentage of their customers on a daily basis. Thus, staff should take advantage of this highly favorable situation by focusing on and improving their listening and general communication skills. A one-day staff development workshop dealing with this area could be extremely beneficial to customers, staff, and the library itself.

\section{STRATEGIES FOR ENHANCED MANAGEMENT}

In conjunction with the development of ongoing relationships with their students and faculty, academic librarians should also undertake several new initiatives in the area of management or administration. In this area, librarians have greater control over the key relevant factors; as a result, they are better able to produce significant results. Key areas on which librarians should focus include service quality, management systems, decision making and supervision, and staff interpersonal relations.

While technology will remain central to academic library operations, librarians must also direct considerable attention toward the concept of service quality. Basically, academic librarians will need to undertake a comprehensive self-examination to ensure that their service delivery systems coincide with and are appropriate to students' and faculty members' expectations and needs. The result likely will be a realignment of policies and management systems aimed to reinforce service quality. As a part of 
this, librarians will clarify customer service priorities (based upon the results of customer research), establish more convincingly the idea of the library's accountability to students and faculty among other constituencies, promote calculated risk taking, and eliminate superfluous checks and balances.

Hearing complaints and other input directly from customers provides library managers with a more compelling reason to work with other staff for the modification of the service delivery process.

Consequently, librarians will be engaged in the rather uncommon task of setting service priorities and attainable service quality targets. Accompanying this will be a redeployment of resources after customers have identified the varying degrees of importance they attach to the services offered by the librarians. Thus, library staff not only will see their work responsibilities redesigned as tasks that add no value for the customer are eliminated but they also will participate in a performance evaluation process that is directly linked to service quality. Finally, the academic library that wishes to remain a viable provider of services to students and faculty will need to completely integrate its services. This can be accomplished by physically locating them together to enhance communication with and understanding for customers who then will experience reduced travel times and distances when using services that are related. Librarians could consider the creation of a singleservice point for reference and information services (without regard for material format) and interlibrary loan/document delivery. While staff who have specialized expertise in some of these areas would continue to work, the customer would perceive a seamless provision of service based on fewer divisions.

As librarians in large academic libraries conduct their self-study of management systems, many will find that organizational structures may be sufficiently complex and bureaucratic to impede the provision of quality services. One manifestation of this problem is an excessively high number of staff with no direct contact with students, faculty, and other customers. In addition, too many levels of management may inhibit both upward and downward communication between managers and service personnel. Particular attention should be given to either the reconfiguration or elimination of these nonservice positions. Likewise, top managers need to ensure that staff in public contact positions forward customer input to managers. In addition, those managers should adopt a practice common to executives in other service industries such as retailing and lodging-periodically spending time in positions that provide direct contact with the public. Hearing complaints and other input directly from customers provides library managers with a more compelling reason to work with other staff for the modification of the service delivery process.

Academic libraries are not appreciably different from the majority of service or manufacturing organizations often characterized by a rather rigid hierarchical structure for decision making. Typical environments involve one or more managers who make policy or procedure decisions, with or without input from staff in key public contact positions, and who then direct the staff having responsibility for implementing those policies or procedures.

Upper-level academic library managers need to confront the issue of control, and simultaneously realize that for today's leaders the element of control no longer occupies such a central position. Although it may be considered somewhat trite, the concept of staff empowerment definitely has merit and is worthy of consideration by most academic librarians. Perhaps the most extreme (in a positive sense) situation is one in which staff at the library's various service points possess the flexibility needed for resolving service problems that they encounter. Decision-making authority 
should be pushed down to the lowest level possible so that staff involved in direct contact with customers possess the ability to make those decisions that directly affect their operations, their customers, and themselves. In many libraries, however, evolution rather than revolution may be more appropriate. In those instances, managers need to involve as many staff as possible, emphasize teamwork, and, in general, create a cooperative, nonconfrontational, participative work environment. Managers also need to provide proper training if this empowerment is to succeed.

Staff interpersonal relations is by no means the least significant area upon which academic librarians should focus in order to enhance customer satisfaction and meet customer expectations. In fact, this may be the most critical element if it is valid to assume that the overall work environment is largely responsible for the degree to which library staff attempt to promote customer satisfaction.

As mentioned earlier, no effort to enhance customer satisfaction will succeed unless students and faculty are convinced that library staff, as service providers, care about the quality of service they provide and the manner in which they do it. However, library staff will not demonstrate a high degree of commitment and caring unless they believe that library management cares about the staff as well. Simply put, cus- tomer satisfaction equals employee satisfaction. Library managers need to ensure that they provide staff with sufficient incentives to do things right and to promote customer satisfaction. In addition, managers must treat their colleagues with respect and trust, as human beings rather than mere agents employed in carrying out tasks. Lastly, each academic library that is successful in meeting customer expectations will recognize and reward people not only for their performance but also for identifying problems and developing solutions.

One other strategy that library managers should use involves human resources. Hiring officials should make a concerted effort to employ frontline staff who possess excellent interpersonal skills together with a strong service orientation. For continuing staff, managers have the obligation to provide the proper training that will result in enhanced service.

The shift from a perspective centered on either collections or systems to a focus on students and faculty as customers represents a formidable challenge for academic librarians and their colleagues. However, just as library staff have learned to cope with declining budgets and manipulate a dizzying amount of information resources and technology, so too can they successfully make the transition to establishing customer satisfaction as their overriding goal.

\section{REFERENCES AND NOTES}

1. Charles B. Osburn, "Issues of Structure and Control in the Scholarly Communication System," Library Quarterly 54 (Jan. 1984): 90.

2. Douglas Zweizig, "With Our Eye on the User: Needed Research for Information and Referral in the Public Library," Drexel Library Quarterly 12 (Jan. 1976): 48-58.

3. Russell Shank, "New Expectations from Users of Academic Libraries," in Priorities for Academic Libraries, ed. Thomas J. Galvin and Beverly P. Lynch (San Francisco: Josey-Bass, 1982), 25-34.

4. Andrew Green, "What Do We Mean by User Needs?" British Journal of Academic Librarianship 5, no.2 (1990): 65-78.

5. Donald W. King and Vernon E. Palmour, "User Behavior," in Changing Patterns in Information Retrieval, ed. Carol Fenichel (Washington, D.C.: American Society for Information Science, 1974), 7-33.

6. Green, "What Do We Mean by User Needs?" 76.

7. Ibid.

8. Philip Rzasa and Norman Baker, "Measures of Effectiveness for a University Library," Journal of the American Society for Information Science 23 (July/Aug. 1972): 248-53. 
9. Robert W. Burns, Jr. "Library Use as a Performance Measure: Its Background and Rationale," Journal of Academic Librarianship 4 (Mar. 1978): 4-11.

10. Jeffrey E. Disend, How to Provide Excellent Service in Any Organization (Radnor, Pa.: Chilton, 1991).

11. Valarie Zeithaml, Leonard Berry, and A. Parasuraman, "Communication and Control Processes in the Delivery of Service Quality," Journal of Marketing 52 (Apr. 1988): 38.

12. J. Douglas Adamson, "Creating the Unexpected ... and Moving beyond Perceptions," Bank Marketing 20 (Dec. 1988): 4-5.

13. Valarie Zeithaml, A. Parasuraman, and Leonard Berry, Delivering Quality Service: Balancing Customer Perceptions and Expectations (New York: Free Pr., 1990), 19.

14. A. Parasuraman, Leonard Berry, and Valarie Zeithaml, "Understanding Customer Expectations of Service," Sloan Management Review 32 (Spring 1991): 39-48.

15. Zeithaml, Parasuraman, and Berry, Delivering Quality Service, 20.

16. Kathleen Sanford, "The Customer Isn't Always Right," Supervisory Management 34 (Oct. 1989): 30.

17. Parasuraman, Berry, and Zeithaml, "Understanding Customer Expectations," 39.

18. Valarie Zeithaml, Leonard Berry, and A. Parasuraman, The Nature and Determinants of Customer Expectations of Service (Cambridge, Mass.: Marketing Science Institute, 1991).

19. Michael D. Johnson and Claes Fornell, "A Framework for Comparing Customer Satisfaction across Individuals and Product Categories," Journal of Economic Psychology 12(June 1991): 276.

20. Ibid., 275.

21. Ruth N. Bolton and James H. Drew, "A Multistage Model of Customers' Assessments of Service Quality and Value," Journal of Consumer Research 17 (Mar. 1991): 383.

22. Zeithaml, Parasuraman, and Berry, Delivering Quality Service, 40.

23. Shank, "New Expectations from Users," 25.

24. Zeithaml, Parasuraman, and Berry, Delivering Quality Service, 125.

25. Joan Uhlenberg, "Redefining Customer Expectations," Quality 31 (Sept. 1992): 34.

26. Zeithaml, Parasuraman, and Berry, Delivering Quality Service, 60.

\section{IN FORTHCOMING ISSUES OF COLLEGE \& RESEARCH LIBRARIES}

\section{Forum:}

Potential Collection Development Bias: Some Evidence on a Controversial Topic in California

David A. Harmeyer, with responses from three academic librarians

Job Satisfaction among Support Staff in Michigan Academic Libraries

Julie Voelck

Archimedes: Analysis of a HyperCard Reference Tool

Jim Ottaviani 


\section{(舟}

\section{T IME TO CONSIDER}

OUTSIDE CATALOGJNG HELP?

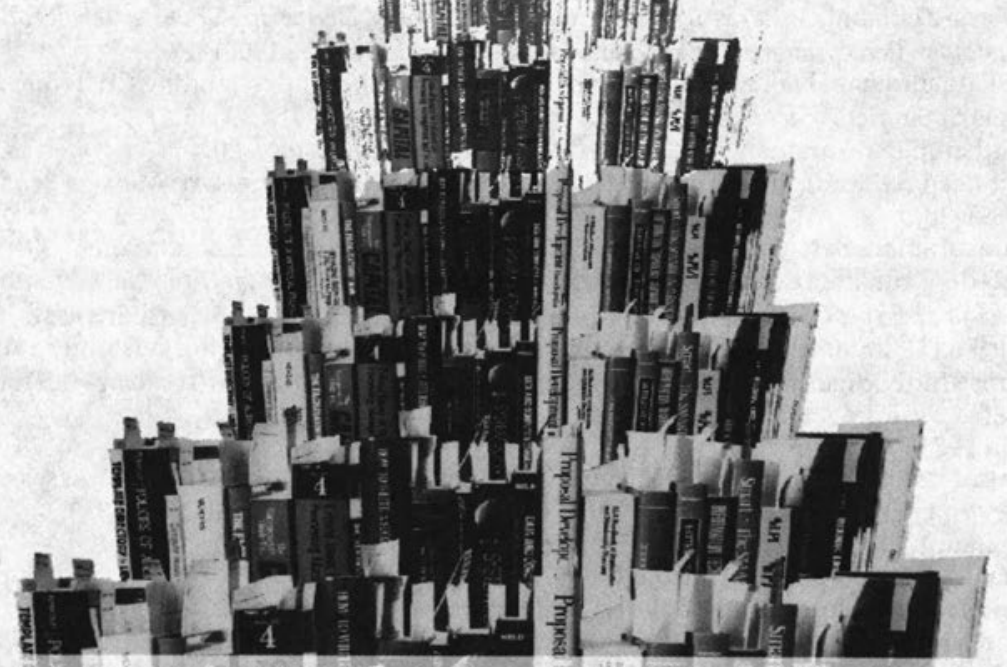

4. TH E O C L C T E C H P R O S E R Y I C E
IT WHEN YOU NEED HEIP WITH A BACKLIOG OR ONGOING SUPPORT, OCLC TECHPRO STAFF CAN MAKE FAST WORK OF YOUR

\section{UNCATALOGED MATERIALS.}

Technical reports. Difficult formats. Foreign language items. Special collections. Or everyday material. Ohio-based TECHPRO staff will meet your cataloging specifications and your quality demands.

And at a reasonable price. In fact, many libraries discover that TECHPRO lowers their cataloging costs and frees up time for other projects. As your library strives to become more efficient while maintaining your high level of service, shouldn't you explore the OCLC TECHPRO Service?

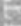
OCLC 800-848-5878 6565 Frantz Road, Dublin, Obio 43017-3395

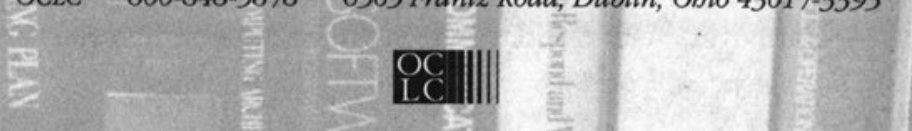

FURTHERING ACCESSTO THE WORLD'S INFORMATION

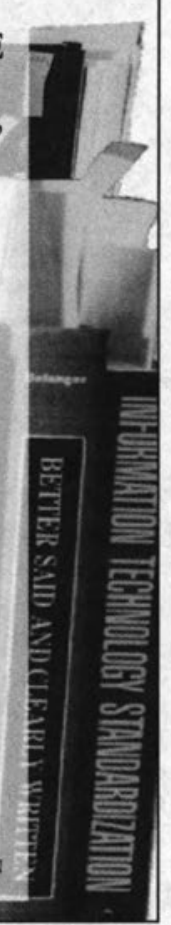

